\title{
MANAGEMENT OF CHALLENGES DURING THE CONSTRUCTION OF OFFSHORE FACILITIES
}

\author{
OVE T. GUDMESTAD \\ University of Stavanger, Norway.
}

\begin{abstract}
The construction of offshore facilities for development of oil and gas deposits is preceded by careful Conceptual Studies, Front-End Engineering Design Studies (FEED studies) and a Detailed Engineering phase including accurate construction planning. Still, incidents during the Construction Phase could lead to needs for implementation of physical strengthening of construction details or changes to the construction process. These incidents could emerge from information coming from the construction of other facilities, detection of design errors or aspects which were overseen during the engineering phase. Serious consequences, like loss of assets or fatalities, could occur in case the unexpected information was not assessed and changes were not implemented.

In this paper, we report on how the design and construction processes were adjusted during the construction phase of the largest of the North Sea platforms, the Troll offshore gas production facilities, as new information became available while the platform was in the construction phase.

The assessment of all incoming information and implementation of mitigating measures led to the successful construction, installation and start-up of gas production from the platform. Of particular importance for the success was the open attitude by the operator of the construction project to allow for voicing of concerns from companies hired to do verification, external reviewers and from project personnel.

The lessons learned during the construction of these facilities could be very useful for those involved in the design and construction of large projects, in particular in offshore oil and gas projects where the forces due to waves and currents and the strains due to bending and pressures are not always well known initially.

The paper is concluded by a recommendation to listen to those presenting warnings to project management during project execution (including the detailed engineering and construction phases). Keywords: Construction risk analysis, Early warnings, Handling of badnews in a project, Implementation of concerns from lower level specialists, Management challenges, North Sea gas, Ringing phenomena, Loss of the Sleipner concrete Platform, Troll concrete platform, Use of GRP piping.
\end{abstract}

\section{INTRODUCTION}

The Troll field is the largest gas field in the North Sea. The field is located in the Northern North Sea. The gas is being produced through a large fixed concrete gravity base platform located at the field in $305 \mathrm{~m}$ water depth. At the platform, gas is produced, dried and compressed and sent to onshore process facilities located at Kollsnes, $65 \mathrm{~km}$ to the west. The gas production started in 1995 from the reservoir located $1400 \mathrm{~m}$ below sea floor. The production is kept up by recent installation of compression units on-board the platform.

The Troll field also contains a relatively thin layer $(22-26 \mathrm{~m})$ of oil underneath the gas column and the oil is produced from two floating rigs. The total investments in the field development (actual and planned) are in the range 40 billion US \$ [1]. In 2018, the total production from the field was $46 \mathrm{MSm}^{3}$ of oil equivalents. It is expected that the field could continue to produce gas until year 2100. Original reserves were in terms of $\mathrm{MSm}^{3}$ oil equivalents as follows: oil: 285.7, gas: 1432.2, NGL: 45.6, condensate: 1.5. The Norwegian government has recently approved plans for production to year 2050 [2], whereby 2.2 billion barrels of oil equivalents can be produced.

The licence was awarded to a consortium with A/S Norske Shell as operator in 1979. The reservoir was confirmed later in 1979. The field was declared commercial in 1983 following 
reservoir confirmation and conceptual engineering studies. After construction/ platform installation, Equinor (formerly Statoil) took over as field operator in 1996. The Shell group has still a large equity $(8.1 \%)$ in the field.

\section{PROJECT MANAGEMENT ISSUES}

Complex engineered projects may face technical or managerial challenges that could lead to failures or disasters. There are several reasons why this could happen:

- In several projects the technical concept is not sufficiently engineered when project execution starts, so conceptual engineering must continue into the project execution phase (including the detailed engineering and construction phases) where the time pressure normally is an issue. The Yme project on the Norwegian shelf [3] is an example of a project where the increased topsides of the production jackup structure grew to such an extent that the natural period of the structure came into resonance with a large number of waves. Fatigue damage resulted. The structure became unsuitable for the purpose and had to be removed (scrapped) from the offshore site at huge costs, even before any barrel of oil was produced.

- In other cases, the handover from the Concept Engineering team and/or the Front-End Engineering (FEED) team to the Project Execution team is not thorough. This could easily lead to implementation of misunderstandings or undesirable technical solutions. An example of such case, is a semisubmersible offshore production unit that was optimized in the FEED phase by specifying that the living quarter module should be built in aluminium. The project, however, ordered the cheaper steel living quarter whereby the additional weight of steel over aluminium caused the need for larger buoyancy and thereby gave rise to larger anchor forces acting on the structure.

- Projects implementing new technologies or representing extension of state of art technology must, through the project execution, keep alert to ensure that no unknown factors are overseen.

- Challenging situations could easily be caused in case of overconfidence by the management team in trusting their own assessments; in this case, there would be no listening to concerns from external reviewers or from internal project staff.

A comprehensive review of early warning signs in complex projects has been carried out by Williams et al. [4]. They discuss why early warning signs often are overseen and conclude that such type of information normally represents a disruption to the project execution plan. The discussion has been further detailed by Haji-Kazemi et al. [5] who have reported on barriers that hinder response to early warning signs. They conclude that 'barriers may develop due to organizational factors, such as project managers' optimism bias, the normalization of deviance within an organization, and the lack of an outside view'.

The inquiries following disasters show that in many cases there were individuals who may have spoken up, but been overruled [6]. Some project persons, therefore, decide to go public with their concerns. They are called 'whistleblowers' and may be prosecuted, even if their information causes changes in the project so a disaster is avoided. In the case of severe technical or organizational problems in a project, the company management in cooperation with the project management should react positively at an early stage to early warnings and shift attention from embarrassment to careful considerations of the 'bad news' being voiced. The results could be a project getting back on schedule and on planned costs, while technical issues (potentially causing large failures) are resolved. 
Therefore, also in later project phases, issues that could lead to failures must be investigated, even if such investigations could lead to delays and additional project costs. In the following sections, we report on how challenging information was assessed and incorporated into one of the largest engineered projects in Norway, the Troll gas production platform.

It must be noted that if a project 'cannot afford safety', the costs of an accident, a failure or even a disaster could be more than the company could manage. In this respect, it is sufficient to mention the Challenger disaster [8] influencing strongly on the perception of NASA and the Deepwater Horizon disaster [9] that totally changed the way BP, one of the world largest corporations, sees the risk picture.

\section{THE DEVELOPMENT AND CONSTRUCTION OF THE TROLL OFFSHORE FACILITIES}

The Troll gas production unit was initially planned to produce sales gas at the field from a huge fixed production unit. A bottom supported fixed unit was selected as technology for risers, having sufficient size to produce the very large amounts of gas, were not available at the time of project approval.

Due to the large water depth at the location $(305 \mathrm{~m}$ ), the platform natural period (of about 5 s) would get in resonance with the energetic part of the wave spectrum. Furthermore, the huge facilities required (close to 50,000 tonnes topsides equipment) would be very costly to install offshore. It was therefore decided [9] to dry the gas offshore and send the gas and NGL/condensate to shore facilities for full processing to sales gas and NGL. The pipelines from the platform to shore had to be injected with Mono-Ethylene-Glycol (MEG) to avoid the formation of free water that could cause corrosion. This simplified the topsides facilities and the principles developed for the Sleipner gas/condensate platform, further south in the North Sea could be applied [10]. Through this simplification, the topsides weight was reduced to 22,500 tonnes.

During the engineering phase of the concrete gravity platform that supports the topsides facilities [11], several ingenious technical aspects were introduced:

- A foundation system consisting of $30 \mathrm{~m}$ long open skirts was developed to ensure that the weight of the structure and the loads caused by waves and currents were transferred down to competent soils at $30 \mathrm{~m}$ below mudline.

- Four vertical columns/legs were designed to support the topsides, these columns were kept connected (by a 'Rigel') at mid height ( $150 \mathrm{~m}$ below surface) to reduce the total displacement of the columns at the surface level and at the connections of the columns to the deck/the topsides equipment, thereby reducing stresses in columns and at connections to the topsides.

- The topsides area was fixed supported to the two columns at the outer edges, while the topsides were elastically supported by the centre columns; thus, forces transmitted to the deck structure were minimized.

- The concrete design was optimized, using high density concrete (concrete quality C70) and light weight aggregate (near to the top of the columns) to reduce the weight of the upper part of the columns (and thus reducing the height of the centre of gravity of the platform during the tow-out to the field).

- The required concrete cover of the steel rebars was tested to ensure corrosion resistance throughout the estimated 70 years of lifetime of the platform (later the platform was epoxy painted in the waterline to ensure that water would not penetrate to the steel rebar reinforcement).

- A technical team with engineers from the Shell group and Statoil worked with the contractors to ensure that all aspects of the design were covered. 


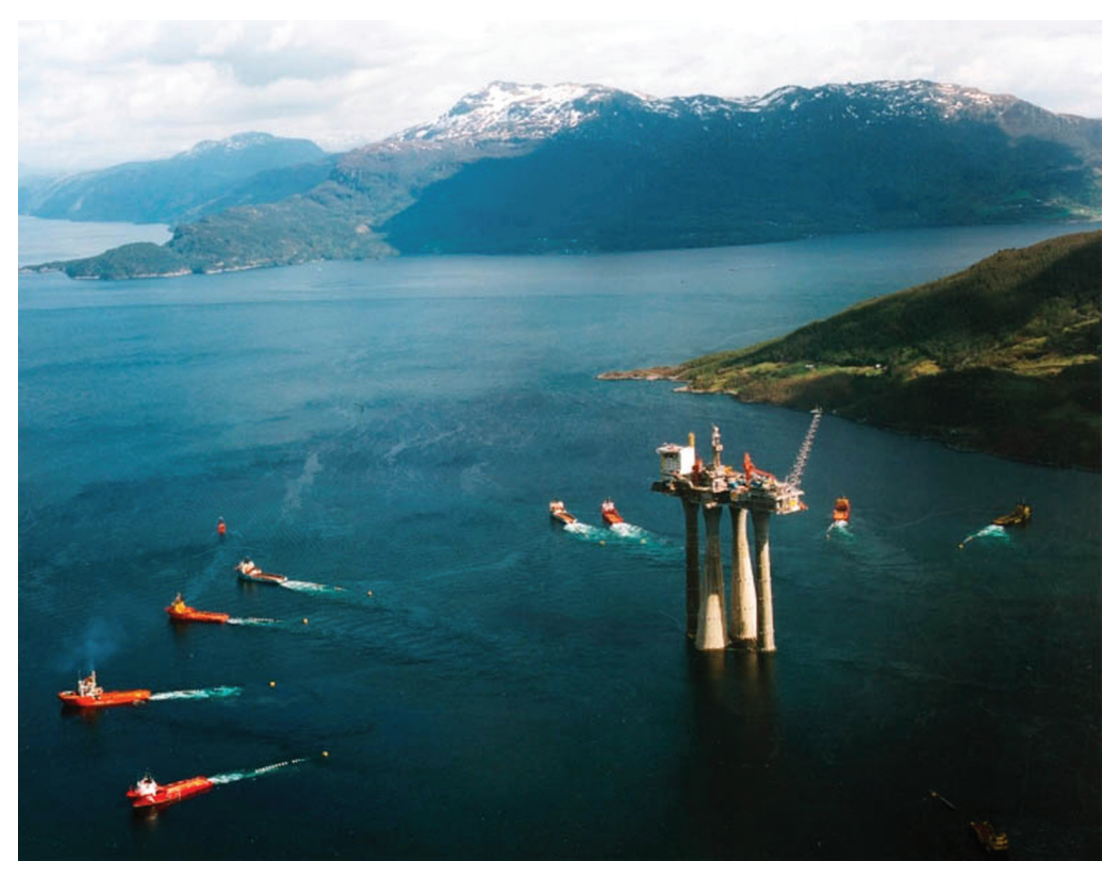

Figure 1: Towing the Troll concrete gravity platform to the offshore site throughout Norwegian fjords (Picture: Equinor/Statoil).

- An independent company (Det Norske Veritas) was hired to review/verify all design calculations.

The concrete construction started in a dry dock near Stavanger in July 1991 and the platform was towed to the offshore site in July 1996. The platform base was constructed in the dry dock; thereafter, the base part of the structure was towed to a deep-water site (Vats in northern part of the Rogaland County) where the columns were slip-formed. While construction proceeded, the platform was submerged to keep the working platform at reasonable height above the sea level to allow for access by personnel.

In parallel with the concrete platform construction, the steel deck and drilling/production facilities were finalized. All parts were then moved to a deep fjord near the Aker Stord construction yard for final mounting of the deck onto the concrete part and for commissioning of all facilities. Following the tow to the offshore site (Fig. 1), the fully operational platform immediately started to drill production wells and gas production started in September 1996.

\section{INCIDENTS INFLUENCING THE CONSTRUCTION OF THE TROLL OFFSHORE CONCRETE GRAVITY BASE PLATFORM}

As the construction of the Troll concrete gravity platform advanced, several challenging situations appeared and new information became available, [12]:

In parallel with construction of the Troll gravity base structure, A/S Norske Shell, as operator for the Draugen offshore oil field in the Norwegian Sea constructed a mono-tower concrete gravity structure for the development of this field located in $270 \mathrm{~m}$ water depth. The topsides facilities were in the order of 30,000 tonnes. During the construction phase, final 
wave model tests of the Draugen platform were carried out in the wave tank at Marintek in Trondheim to confirm the wave loading and the design. The reasons for conducting these last minutes tests were that large dynamic oscillations were identified during the ongoing design of tension leg platforms (TLPs) for deep-water applications, [13]. These tests, unfortunately, showed that the Draugen platform experienced very large oscillations in case of large waves. These oscillations were characterized as being of a 'ringing'/transient type. The associated stresses in the Draugen mono-tower were much higher (up to $70 \%$ in certain cross-sections) than the original design had accounted for.

The problem was solved by making the slender part of the platform (penetrating the sea surface) higher/longer than the original design, whereby the load attracted on the column from the waves was reduced. Note that the column had to be widened to a larger square area at the top to support the deck/topsides. Furthermore, the amount of reinforcement was increased along the vertical column.

The ringing phenomenon is regarded as a higher order nonlinear response phenomenon caused by steep and large waves $[14,15]$. The ringing phenomenon identified in the model tests was confirmed as an actual phenomenon during an incident the first year after the platform was installed at site [16].

Furthermore, Statoil was during the same period in the process of finalizing the construction of the Sleipner A gas/condensate gas production platform for $80 \mathrm{~m}$ water depth to be located in the central North Sea. The project was considered a state of art construction project as the platform was the twelfth in a series of concrete gravity platforms being constructed by the company Norwegian Contractors for the North Sea. Therefore, much efforts were implemented to reduce the costs of the gravity base platform. The deck and topsides facilities, on the other hand, were given much attention with implementation of a safe large module layout arrangement for the production equipment [10].

However, on August 23rd 1991, during a controlled ballasting operation in preparation for transferring the deck over the platform ('deck mating'), the Sleipner platform sank. All persons on-board the platform at the time were fortunately rescued by nearby boats. The sinking resulted in a series of investigations and laboratory tests [17]. It was concluded that the loss was caused by a design failure in a cell wall, resulting in a serious crack and a subsequent major leakage. The wall failed as a result of an error in the finite element analysis (triangular finite elements were used in a high stress zone (Fig. 2), even if the FEM program manual (Nastran) warned about the use of such elements in highly stressed areas).

The failure of the analysis led to $47 \%$ underestimation of shear stresses in a critical region and subsequently to insufficient reinforcement and insufficient anchorage of the reinforcement in the critical zone. As soon as the investigation was concluded, the construction of a second Sleipner A was started, this time, with sufficient reinforcement and with careful steel stirrups reinforcement keeping the rebars connected across the cross-section of the concrete wall in all critical sections of the platform.

The failures causing the Sleipner A sinking could be seen as the result of the optimizing process:

- The concept report (the pre-engineering report) called for very thorough design reviews of critical areas of the foundation caisson where circular foundation cells were joined by triangular geometry cells, tri-cells. This was emphasised because there had been an incident with another concrete platform (Statfjord A) where leakages in these critical sections were observed. 


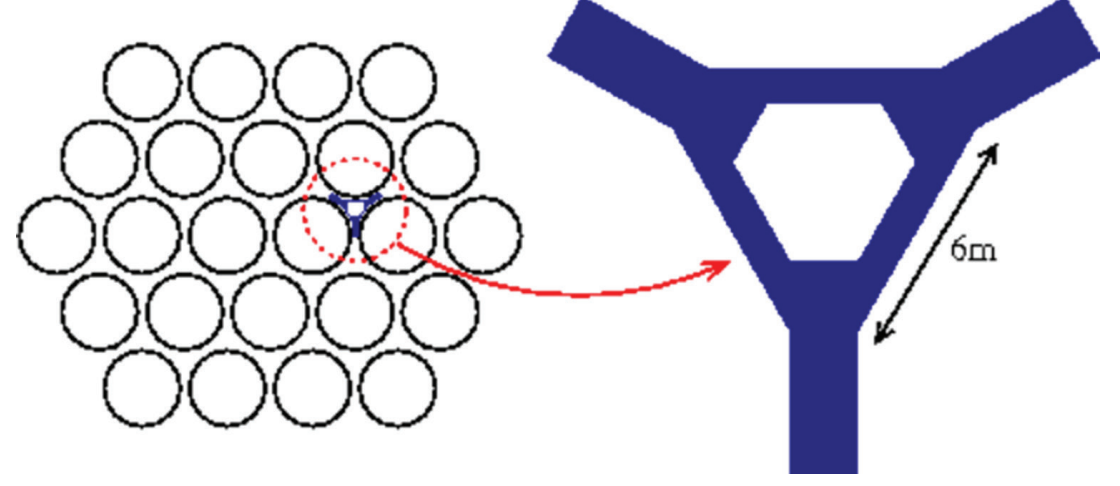

Figure 2: Failure in design of tri-cells of the Sleipner A platform.

- The design team was not fully familiar with the finite element program, the Nastran FEM program, having used the SESAM Finite Element program previously. Note that there were savings by selecting the Nastran code (the leasing costs of this program were lesser that the previously used FEM program).

- The company in charge of the independent verification of the design suggested that it would be necessary with separate FEM analysis of critical regions of the platform. This suggestion was not approved by the operator as a change order, as the project was in a cost saving mode.

- The standard internal checking of stresses by use of simplified beam models is not carried out.

It should be noted that the warnings by those in charge of the pre-engineering and the suggestions by the company in charge of the independent verification were considered, however, not implemented as suggested. The link between the project management and the lower level engineering staff and the independent reviewers did not work as needed in this project, causing a 600-million-dollar loss.

Following the loss of the platform, a new platform with the same geometry, however, with proper reinforcement was constructed. One of the partners in the licence involved themselves strongly by sending one of their most experienced engineers, specializing in concrete design, to join the project group.

\section{ADJUSTMENTS DURING THE CONSTRUCTION OF THE TROLL PLATFORM}

The project management of the Troll construction project was following closely the progress of the other ongoing platform construction projects. This resulted in immediate actions:

- The potential for ringing response was checked out by additional wave tank tests and all measures already implemented for the Draugen design were implemented for the Troll platform.

- The tri-cell design was given particular attention and the anchoring between the outer and inner reinforcement in the walls were increased

- A separate independent project group was established to carry out construction risk analysis of the entire construction, tow and installation process. The team was given access to all design, construction and maritime documentation $[18,19]$. The team had all the way until final installation at the site the best possible cooperation with the construction management and the parent organization (Shell International in The Hague, The Netherlands). 


\section{ANOTHER ISSUE ARISING THAT COULD HAVE SUNK THE TROLL PLATFORM DURING THE CONSTRUCTION PHASE}

Late during the construction of the Troll platform another design issue arose: During transfer of the deck onto the platform, the deck was to be located on barges, to be positioned between the columns. The platform had therefore to be submerged to a level where the deck on the barges could pass over the top of the columns. This submergence would result in huge water pressure on the platform structure, particularly on the two dry outer columns and the lower parts of the other columns, which, during this operation were only to be partially water filled. After the deck was in place above the shafts, water was to be pumped out of the columns, whereby the deck load was gradually to be transferred from the barges onto the columns of the platform. Parts of the platform would experience their highest loads during this phase.

In order to facilitate the ballasting operations, the installation at the field, and the ultimate removal of the platform from the site after the production period, ballast pipes were cast into the lower domes of the foundation cells and in the bottom of the columns. As the platform was initially designed for a 70-year life, it was decided early in the project to use pipes made of glass-fiber reinforced epoxy (GRVE), as some of these pipes (those for platform removal) had to be designed for the maximum life of the platform. GRVE would provide maximum corrosion resistance and was also thought to provide maximum safety during all project phases. For further protection, some of the pipes located in the bottom of the columns were protected against dropped objects with a concrete cover, Fig. 3.

Traditionally, ductile steel had been used for the different types of pipes in concrete platforms, but GRVE was selected for this application because of the very long service life requirement of the pipes to be used for platform removal. The GRVE pipe material specified for these temporary pipes in the concrete structure was relatively new for this type of structure, and therefore, it was difficult to establish a safety factor for this application. Previous unpublished test results, however, gave some cause for concern.

Late in the construction phase it became evident that there could be a risk of pipe leakage due to the possibility of clipping the 2" and 8" glass-fiber reinforced composite pipes in the riser and utility columns (the outer edge columns) of the concrete platform during submergence testing and deck transfer. Clipping would result from movement between the structural

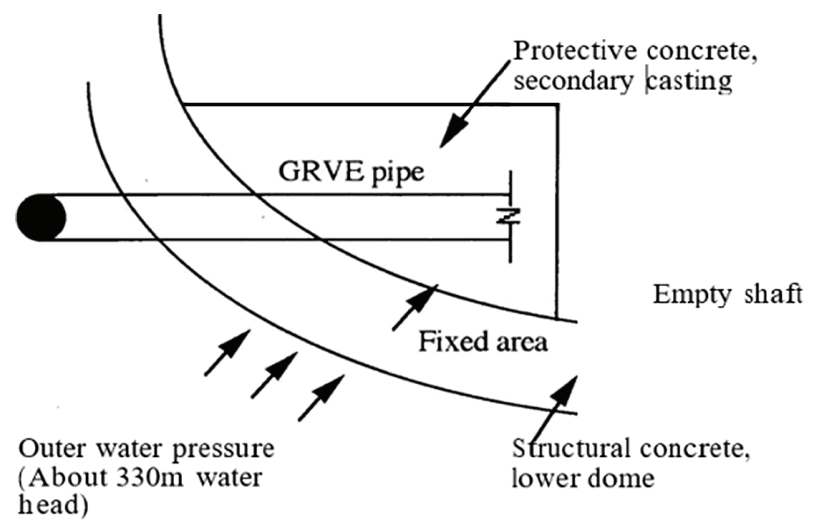

Figure 3: Section of the lower dome of the concrete platform, showing GRVE pipes and protective concrete [20]. 
concrete in the lower domes and the non-structural protective concrete above. Eventually, the clipping could result in loss of the platform due to rapid flooding of these shafts, causing the platform to sink. At this time, the loss of Sleipner A during the submergence phases was fresh in the mind of all involved in the project. The probability of clipping with resulting leakage of one or several of the 8 inches GRVE pipes in the concrete platform was estimated to be $2.6 \times 10^{-1}$ as calculated using the PROBAN software [20]. The failure probability of each individual GRVE pipe was defined as the probability that the local clipping displacement each pipe was exposed to was larger than the clipping capacity for this pipe.

A warning was immediately raised by the test contractor (verification company) checking the capacity of the GRVE piping. An organizational analysis of the decision-making, the level of concern amongst those involved and the estimated risk has been reported by Lakats et al. [20], using methods described in Ref. [21]. Interviews and discussions were conducted with several of the persons involved, including persons from multiple organizations and at multiple levels of authority. The organization can be described in terms of the key communications that took place in the case. The communication paths can be summarized as a social network [22], as shown in Fig. 4.

Nodes represent individuals or groups involved in the communication, while arrows indicate communication links. Nodes are labeled with a three-digit code: the first digit reflects the organization to which the person belongs: $1=$ test contractor, $2=$ operator, $3=$ operator parent company, $4=$ partner company, $5=$ construction contractor and $7=$ government agency. The second number indicates the persons relative position in their organization (a lower number represents higher level in the organization, while an underscore indicates a group of hierarchical level. The third number is used to distinguish persons at the same level in the same organization.

The merged arrow from 261 and 264 to 251 indicates that the subordinates communicated their views separately, but 251 considered these communications as an aggregate. Where more than one communication was received, numbers above arrows indicate the order in which they were received. Generally, it was assumed that communication within the same organization occurred before communications from external sources.

Due to strong warnings from persons 561 and 481 supported by 261 and 264 as well as 391 , the project organization concluded that action was necessary at a rather high extra cost to the project to reduce the risk of sinking to a very low level [20]: a large number of the vulnerable ballast pipes were plugged, and the platform was submerged only to a minimum level during platform commissioning phase at the Stord Yard prior to tow to offshore site.

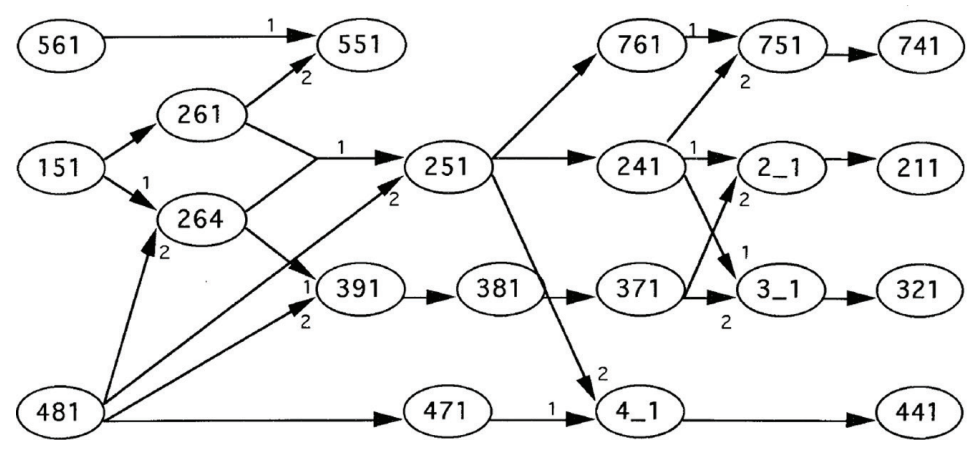

Figure 4: Communication Paths for GRVE Failure Case [20]. 
'Of significant importance was the loyalty and trust within the organization. Often, it is the lower level individuals who recognize the severity of a problem. Without trust in the judgments of subordinates, the hierarchy would block communication of warnings, so that decision makers may lack an accurate perception of the risk on which to base their decisions. At lower levels of the hierarchy, communication among colleagues (both within and across organizations) allows personnel to confirm their concerns regarding potential risks, and provides them with the confidence in their judgments to communicate their concerns to superiors when warranted. This combination of reinforcement at lower levels and trust in subordinates creates an environment that is conducive to the communication of critical warnings. Inclusion of all of the organizations in the communication process created more pathways for the warning to reach decision makers, significantly increasing the likelihood of action being taken' [20].

\section{LESSONS LEARNED THAT COULD BE IMPLEMENTED IN CURRENT CONSTRUCTION PROJECTS}

The discussion presented regarding the management of challenges during the construction of offshore facilities documents the importance of following contemporary activities and adjust design and processes and implement any warning signals. The warning may arise from verifications or reviews and also from lower level personnel in the organization. As the most experienced engineers of an organization often are given specialist tasks to address uncertainties, their concerns must be very carefully addressed [23]. Warning signs cannot be neglected in an organization or in a project [24], even if the information is bothersome and represents 'bad news', additional work, potentially schedule delays and additional costs for the project [25].

We have documented how the management involved during the construction of the Troll gas platform for the North Sea implemented all concerns being transferred from other ongoing projects. The management also implemented warning signs voiced by the independent review team. These warning signs were strengthened by the project staff (including the group carrying out the project construction risk analysis) and the warnings reached the project management who was capable of implementing the concerns raised. Then, the project could continue until successful platform installation.

We have, furthermore, in the paper documented the management process and have emphasised on the working conditions in a project where the different levels of decision makers were in good and respectful communication.

\section{ACKNOWLEDGEMENTS}

The author ('481') acknowledges the cooperation with Mr H. Skjæveland (formerly with A/S Norske Shell, Norway), and with Dr J. H. Vugts of Shell International, The Hague, The Netherlands, during the planning and construction of the Troll concrete gravity platform for the North Sea.

\section{REFERENCES}

[1] Norsk Petroleum, https://www.norskpetroleum.no/en/facts/field/troll/

[2] NRK Rogaland, https://www.nrk.no/rogaland/trollfeltet-skal-levere-gass-til-2050-1. 14329706 (accessed 7 December 2018).

[3] Hannevik, M.B., Lone, A., Bjørklund, R., Bjørkli, C.A. \& Hoff, T., Organizational climate in large-scale projects in the oil and gas industry: A competing values perspective. International Journal of Project Management, 32(4), pp. 687-697, May 2014. https://doi.org/10.1016/j.ijproman.2013.08.006 
[4] Williams, T., Klakegg, J., Walker, D.H., Andersen, B. \& Magnussen, O.M., Identifying and acting on early warning signs in complex projects. Project Management Journal, 43(2), pp. 37-53, April 2012. https://doi.org/10.1002/pmj.21259

[5] Haji-Kazemi, S., Andersen, O. \& Klakegg, J., Barriers against effective responses to early warning signs in projects. International Journal of Project Management, 33(5), pp. 1068-1083, July 2015. https://doi.org/10.1016/j.ijproman.2015.01.002

[6] Vinten, G., Whistleblowing towards disaster prevention and management. Disaster Prevention and Management: An International Journal, 9(1), pp. 18-28, 2000. https:// doi.org/10.1108/09653560010316032

[7] Vaughan, D., The Challenger Launch Decision: Risky Technology, Culture, and Deviance at NASA, Chicago University Press, 1996

[8] The Deepwater Horizon Study Group (under the leadership of professor R.G. Bea), Investigation of the Macondo Well Blowout Disaster, University of California at Berkeley, USA, 2011.

[9] Volden, A., Senior Field Development Engineer, Statoil. Private Communication.

[10] Gudmestad, O.T. \& Coker, J.W.A., The sleipner a platform, an efficient gas and condensate installation. Proc. European Petroleum Conference, Europec 88, pp. 111-126, London, October 1988.

[11] Huslid, J.M. \& Gudmestad, O.T., The troll platform project, Proc. Int. Congress Major Engineering Projects in the World, pp. 87-104, Nice, June, 1988.

[12] Skjæveland, H., Knudsen, A. \& Nyborg, A., Technical challenges in the design and construction of the troll gravity base structure. Proceedings of ISOPE, 1-94-302, Osaka, 1994.

[13] Kumar, A. \& Kim, C.H., Ringing of heidrun tlp in high and steep random wave. International Journal of Offshore and Polar Engineering, 12(3), 2002.

[14] Faltinsen, O.M., Newman, J.N. \& Vinje, T., Nonlinear wave loads on a slender vertical cylinder. Journal of Fluid Mechanics, 289, pp. 179-198, 25 April 1995. https://doi. org/10.1017/s0022112095001297

[15] Hellevik, K. \& Gudmestad, O.T., Limit cycle oscillations at resonances for systems subjected to nonlinear damping or external forces. Journal of Physics: Conference Series (JPCS), 2017.

[16] Gundersen, N.G., Platform Manager at the Draugen Platform During a "Ringing" Event in March 1995, Private communication.

[17] Jakobsen, B., \& Rosendal,F., The sleipner platform accident. StructuralEngineering International, 4(3), pp. 190-193, August 1994. https://doi.org/10.2749/101686694780601971

[18] Trbojevic, V.M., Bellamy, L.J., Brabazon, P.G., Gudmestad, O.T. \& Rettedal, W.K., Methodology for the analysis of risks during the construction and installation phases of an offshore platform. special issue: "Safety on offshore process installation: North Sea." Journal of Loss Prevention in the Process Industries, 7(4), pp. 350-359, 1994. https:// doi.org/10.1016/0950-4230(94)80049-9

[19] Trbojevic, V.M., Ballamy, L.J., Gudmestad, O.T., Aarum, T. \& Rettedal, W.K., Assessment of risk in the design phase of an offshore project. Proc. OMAE 96' - Vol. II. Safety and Reliability, pp. 431-435, 1996.

[20] Lakats, L., Gudmestad, O.T., Skjæveland, H., Rettedal, W. \& Gausel, E., Managing Offshore platform construction taking into account "bad news." A case study. Paper WAO6.4 Presented at Institute for Operations Research and the Management Sciences, National Meeting, Montreal, Quebec, https://www.researchgate.net/ publication/313553887_Managing_Offshore_platform_construction_taking_into_ account_bad_news_A_case_study (accessed 26-29 April 1998). 
[21] Lakats, L.M., Organizational warnings and system safety: designing for the communication of bad news. Doctoral Dissertation, Department of Industrial Engineering and Engineering Management, Stanford University, USA, 1997.

[22] Wasserman, S. \& Faust, K., Social Network Analysis: Methods and Applications, Cambridge University Press, New York, 1994.

[23] Pate-Cornell. M.E. \& Fischbeck, P.S., Safety of the thermal protection system of the space shuttle orbiter: quantitative analysis and organizational factors, Report to The National Aeronautics and Space Administration, December, 1990.

[24] Pate-Cornell, M.E. \& Rettedal, W.K., Management of resource, constraints and system safety: application to the design and construction of concrete offshore platforms. Presented at ISOPE 97, Honolulu, July 1997.

[25] Gudmestad, O.T., Treatment of "bad news" in a project, Proceedings of the 24th Int. Congress on Condition Monitoring and diagnostics Engineering management, ISBN 09541307-2-2, pp. 1035-1041, Stavanger, June 2011. 